\title{
Neurological Disorders in Pregnancy and Puerperium
}

\author{
Sarella LK, Rao DS,
}

\section{Abstract \\ Objectives: To study the clinical profile of the patients presenting with neurological disorders during pregnancy and puerperium.}

Methods: The study was carried out at Government General Hospital, Kakinada, Andhra Pradesh, India between June 2006 and May 2007. Patients in pregnancy, postabortal and postpartum period evaluated in Neurology out-patient and in-patient departments and referred to Neurology department, Government General Hospital, Kakinada during this time were included in this study.

Results: A total of 55 patients presented during pregnancy and puerperium with neurological disorders. Age of the patients ranged from 17 to 31 years. The total number of deliveries in this hospital during this period was 9726. Out of 55 patients Epilepsy-27[49.09\%], Eclampsia-11[20\%], Cerebro vascular disorders-6[10.9\%], Neuropathies $-4[7.27 \%]$, Extrapyramidal disorders---2[3.64\%], CNS infections-Tubercular meningitis $-1[1.81 \%]$, Myelopathy-1[1.81\%], Toxic/ metabolic encephalopathy-1[1.81\%].

Conclusions: Epilepsy was the most common neurological condition followed by Eclampsia and Cerebrovascular diseases. Health education measures for prospective mothers regarding the appropriate, adequate and regular use of anti-epileptic drugs should be taken up. Diligent care is to be taken to watch for neurological deficit in cases of Pre-eclampsia/ Eclampsia to identify special investigation team-Obstetrician, Neurologist, Physicians and Neurologist. The treating team should have the complete knowledge of the effects of rare neurological disorders during pregnancy and puerperium.

Keywords: Epilepsy, Eclampsia, Cerebrovascular disorders, Chorea gravidarum, GuillainBarre syndrome.

\section{INTRODUCTION}

Pregnancy is a time of major hormonal and other physiological changes that can precipitate new neurological and psychiatric symptoms ${ }^{1}$. Though neurological disorders during pregnancy and puerperium (NDDPP) represent a small subgroup, their range is broad $^{2}$. NDDPP can be classified into three subgroups ${ }^{3}$. 1) Diseases which existed already before pregnancy or appear just by chance (eg: Migraine) 2) Diseases that can display a higher incidence in pregnancy (eg: Cerebrovascular disease) 3) Diseases with neurological

Rangaraya Medical College, Kakinada, Andhra Pradesh, India.

Correspondence: Dr. Lavanya Kumari Sarella

E-mail: lavanyakumarisarella@yahoo.com

Competing interests: None symptoms which occur only with pregnancy. (eg: Pre eclampsia/ Eclampsia).

Identification and management of neurological disorders during pregnancy and puerperium (NDDPP) pose a special challenge to Neurologists and Obstetricians, and they should have thorough knowledge of impact of illness on maternal and fetal outcomes, risks of investigations, specific treatments and safety of breast feeding. As many pregnancies are unplanned, diagnostic and therapeutic decisions should be taken to balance their beneficial and adverse effects on mother or child ${ }^{1}$. It is ideal to consider every woman in reproductive age to be potentially pregnant from the very first visit ${ }^{1}$.

\section{METHODS}

This study was conducted in Government General Hospital, Kakinada between June 2006 and May 2007. All patients in pregnancy, post abortal and postpartum period, evaluated with detailed history, clinical examination and basic investigations in department of Neurology were included in this study. CT, MRI nerve conduction studies and other investigations were done as required. Wherever possible a definitive diagnosis was established based upon standard diagnostic criteria.

\section{OBSERVATIONS}

A total of 55 patients presented during pregnancy and puerperium with neurological disorders. Age of

\begin{tabular}{|lcc|}
\hline \multicolumn{3}{|c|}{ Table 1. Distribution of Neurological Disorders during Pregnancy and Purperium } \\
\hline \multicolumn{1}{|c|}{ Disease } & No. of Cases & Percentage \\
\hline Epilepsy & 27 & 49.09 \\
\hline Eclampsia & 11 & 20.00 \\
\hline Cerebrovascular disease & 6 & 10.90 \\
\hline Neuropathies & 4 & 7.27 \\
\hline Extra pyramidal disorders & 2 & 3.64 \\
\hline Primary muscle disorders & 2 & 3.64 \\
\hline CNS infections & 1 & 1.81 \\
\hline Myelopathy & 1 & 1.81 \\
\hline Toxic/metabolic encephalopathy & 1 & 1.81 \\
\hline
\end{tabular}




\begin{tabular}{|lc|}
\hline \multicolumn{2}{|c|}{ Table 2. Clinical Features of Patients with Epilepsy } \\
\hline \multicolumn{2}{|c|}{ Time In Relation to Pregnancy } \\
\hline First trimester & $4[14.81 \%]$ \\
\hline Second trimester & $6[22.22]$ \\
\hline Third trimester & $13[48.14]$ \\
\hline Postpartum & $4[14.81]$ \\
\hline Type of Seizure & $1[3.70]$ \\
\hline Partial & $10[37.03]$ \\
\hline Secondary generalized & $16[59.25]$ \\
\hline Primary generalized & $4[14.81]$ \\
\hline Status Epilepticus & $14[51.85]$ \\
\hline Treatment Pattern & $10[37.03]$ \\
\hline Not on any antiepileptic drug & $3[11.11]$ \\
\hline Monotherapy & \\
\hline Polytherapy & \\
\hline
\end{tabular}

\begin{tabular}{|c|c|c|c|}
\hline \multicolumn{4}{|c|}{ Table 3. Cerebrovascular Disorders } \\
\hline S. No & Clinical Disorder & Investigations & Outcome \\
\hline 1 & $\begin{array}{l}\text { 26yr old primi, known HTN right } \\
\text { hemiparesis }\end{array}$ & $\begin{array}{l}\text { CT; Lt ganglionic } \\
\text { hematoma, old lacunar } \\
\text { infarct-Lt. PCA territory }\end{array}$ & $\begin{array}{l}\text { Preterm delivery at } \\
34 \text { weeks. Low birth } \\
\text { weight, residual } \\
\text { hemiparesis }\end{array}$ \\
\hline 2 & $\begin{array}{l}\text { 20yr multi } 1^{\text {st }} \text { trimester. } \\
\text { Recurrent syncopal attacks. } \\
\text { Past h/o Rt. hemiparesis }\end{array}$ & $\begin{array}{lr}\text { CT-old Lt. } & \text { MCA infarct } \\
\text { MRA-s/o } & \text { Takayasu's } \\
\text { arteritis } & \\
\end{array}$ & Normal labour \\
\hline 3 & $\begin{array}{l}\text { 25yr multi known HTN, } 2 \text { weeks } \\
\text { postpartum, sudden loss of } \\
\text { consciousness, Lt. hemiparesis }\end{array}$ & & $\begin{array}{l}\text { Expired within few } \\
\text { hours of admission }\end{array}$ \\
\hline 4 & $\begin{array}{l}22 \text { yr multi 3-4 weeks } \\
\text { postpartum headache, } \\
\text { seizures, Lt. hemiparesis }\end{array}$ & $\begin{array}{l}\text { CT-frontal venous infarct } \\
\text { empty delta sign-SSS. } \\
\text { MR-bilateral venous infacts }\end{array}$ & Recovered well \\
\hline & & MRV_SSS thrombosis & \\
\hline 5 & $\begin{array}{l}\text { 18yr primi, } 2 \text { weeks postpartum } \\
\text { Lt. hemiparesis }\end{array}$ & $\begin{array}{l}\text { CT-Rt. Fronto temporal } \\
\text { hemorrhagic venous infarct }\end{array}$ & Recovered well \\
\hline & & MRV-SSS thrombosis & \\
\hline 6 & $\begin{array}{l}\text { 20yr multipara } 5^{\text {th }} \text { PO LSCS day } \\
\text { headache, Lt. partial seizures }\end{array}$ & $\begin{array}{l}\text { CT-s/o bilateral transverse } \\
\text { sinus thrombosis }\end{array}$ & $\begin{array}{l}\text { Improved with } \\
\text { minimal residual Lt. } \\
\text { hemiparesis }\end{array}$ \\
\hline
\end{tabular}

the patients varied from 17-31 years. The total number of deliveries in this hospital during this period was 9726 . The incidence of NDDPP was 565 per 100,000 deliveries.

Epilepsy: Epilepsy constituted the most common neurological disorder comprising 27 cases [49.09\%].

Eclampsia: Eclampsia was the second most common neurological condition affecting 11[20\%] patients. Out of these, four patients had seizures in third trimester and seven in postpartum period.

Two prime's presented in third trimester had focal neurological deficits. A 30 year old had right hemiparesis with CT scan showing left hemispherical infarct. Course of pregnancy was complicated by antepartum hemorrhage and intrauterine fetal death. Delivery was spontaneous without any maternal morbidity. A 19 year old, was found to be having

parenchymal and subarachnoid haemorrhage on CT imaging. She delivered a preterm still born baby. Maternal condition continued to be precarious and was discharged against medical advice.

Extrapyramidal Disorders: A 22 yr old multi with 6months of gestation and past history of chorea gravidarum, presented with severe generalized chorea. The other was a $23 y$ r old multi in the first trimester with a past history suggestive of rheumatic fever and chorea during her childhood. Both were treated with Haloperidol with good symptomatic improvement with good maternal and fetal outcome.

Primary Muscel Diseases: A 25 yr old second gravida, a known case of Myotonia congenita, with h/o miscarriage, was followed up from $20^{\text {th }}$ week gestation. She had an uneventful course with good maternal and fetal outcome. A 19 yr old primipara presented with quadriparesis on the fourth postnatal day was found to be having hypokalemia and recovered with oral potassium supplements.

Toxic Metabolic Encephalopathy: A $25 \mathrm{yr}$ old multi, admitted on seventh postpartum day with $\mathrm{h} / \mathrm{o}$ chills, rigors and altered sensorium, improved with antibiotics and antimalarial treatment.

Infectious Diseases: A 24yr old third gravida was evaluated in third trimester for headache, vomiting and altered sensorium of 10 days duration, found to be having mild communicating hydrocephalus, and basal meningitis. She improved with antituberculous treatment, delivered at 28 weeks of gestation. She had residual right sided seventh cranial nerve palsy.

\section{DISCUSSION}

The incidence of NDDPP was found to be 566 per 100,000 deliveries. This was much higher than that in previous studies from Hongkong which showed an incidence of 326 per 100,000 pregnancies $^{2}$. A recent study of NDDPP revealed an incidence of 584 cases per 100,000 deliveries ${ }^{4}$, which is similar to that seen in our study. 


\begin{tabular}{|c|c|c|c|}
\hline \multicolumn{4}{|c|}{ Table 4. Neuropathies } \\
\hline S. No & Presentation & $\begin{array}{l}\text { Nerve Conduction } \\
\text { Studies }\end{array}$ & Outcome \\
\hline \multicolumn{4}{|c|}{ Guillain-Barre Syndrome } \\
\hline 1 & $\begin{array}{l}\text { 28yr old multi with 20weeks } \\
\text { gestation with symptoms of } 2 \\
\text { weeks duration }\end{array}$ & $\begin{array}{l}\text { Axonal motor and } \\
\text { sensory neuropathy }\end{array}$ & $\begin{array}{l}\text { Developed respiratory } \\
\text { paralysis. Expired after } \\
\text { 4days }\end{array}$ \\
\hline 2 & $\begin{array}{l}24 \text { yr old primi at } 5^{\text {th }} \text { postpartum } \\
\text { week }\end{array}$ & $\begin{array}{l}\text { Demyelinating } \\
\text { neuropathy }\end{array}$ & Recovered \\
\hline \multicolumn{4}{|c|}{ Idiopathic Facial Palsy } \\
\hline \multirow[t]{2}{*}{1} & \multirow{2}{*}{$\begin{array}{l}25 \text { yr old primi with term gestation } \\
\text { with severe hypertension }\end{array}$} & - & Labor induced \\
\hline & & & $\begin{array}{l}\text { Good maternal and fetal } \\
\text { outcome }\end{array}$ \\
\hline \multicolumn{4}{|c|}{ Bilateral Carpal Tunnel Syndrome } \\
\hline 1 & $\begin{array}{l}31 \text { yr old primi in } 1^{\text {st }} \text { trimester } \\
\text { with diabetes, hypertension and } \\
\text { hypothyroidism }\end{array}$ & 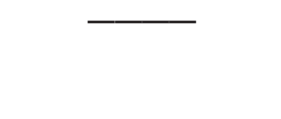 & Improved \\
\hline
\end{tabular}

Table 5. Distribution of Neurological Disorders during Pregnancy and Puerperium Comparision with Previous Studies

\begin{tabular}{|c|c|c|c|c|c|c|}
\hline Condition & TO et al & $\begin{array}{c}\text { Janaki } \\
\text { et al }\end{array}$ & $\begin{array}{c}\text { Srinivasan } \\
\text { et al }\end{array}$ & $\begin{array}{l}\text { Agarwal } \\
\text { et al }\end{array}$ & $\begin{array}{l}\text { Gupta } \\
\text { et al }\end{array}$ & $\begin{array}{l}\text { Present } \\
\text { study }\end{array}$ \\
\hline \multirow[t]{2}{*}{ Total number } & 161 & 97 & 68 & 87 & 76 & 55 \\
\hline & $\mathrm{NO}[\%]$ & NO [\%] & NO [\%] & $\mathrm{NO}[\%]$ & NO [\%] & NO [\%] \\
\hline Epilepsy & 102 [63.3] & $30[30.9]$ & $17[23.5]$ & $5[6.7]$ & 22[28.9] & $27[49.9]$ \\
\hline CVD & $7[4.9]$ & 48 [49.5] & $41[60.3]$ & 72 [82.7] & 9 [11.9] & 6 [10.9] \\
\hline CNS infections & 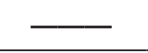 & $4[4.1]$ & $3[4.4]$ & $5[5.7]$ & 12 [15.8] & $1[1.81]$ \\
\hline CNS tumors & $12[7.5]$ & $7[7.2]$ & 16 [23.5] & 16 [23.5] & $1[1.3]$ & $\square$ \\
\hline $\mathrm{PE} / \mathrm{E}$ & 19 [11.9] & $\mathrm{NI}$ & $\mathrm{NI}$ & $\mathrm{NI}$ & $\mathrm{NI}$ & $11[20]$ \\
\hline $\begin{array}{l}\text { Demyelinating } \\
\text { diseases }\end{array}$ & $4[2.5]$ & $1[1.03]$ & $3[4.4]$ & $1[1.1]$ & $1[1.3]$ & - \\
\hline $\begin{array}{l}\text { Peripheral } \\
\text { neuropathies }\end{array}$ & $12[7.5]$ & $1[1.03]$ & $1[1.5]$ & 2 [2.3] & $1[1.3]$ & 4 [7.27] \\
\hline $\begin{array}{l}\text { Metabolic } \\
\text { encephalopathies }\end{array}$ & $\mathrm{NI}$ & $\mathrm{NI}$ & $\mathrm{NI}$ & $\mathrm{Nl}$ & 28 [36.8] & $1[1.1]$ \\
\hline Cord affections & - & $\longrightarrow$ & $5[7.4]$ & $\longrightarrow$ & $1[1.3]$ & 1 [1.81] \\
\hline $\begin{array}{l}\text { Extrapyramidal } \\
\text { disorders }\end{array}$ & - & $\longrightarrow$ & - & - & $\longrightarrow$ & 2 [2.64] \\
\hline $\begin{array}{l}\text { Primary muscle } \\
\text { disorders }\end{array}$ & - & - & - & - & - & $2[3.64]$ \\
\hline I-not included & & & & & & \\
\hline
\end{tabular}

Table 5 shows the results of previous and present studies. ${ }^{2,4,5,6,7}$.

Epilepsy: Epilepsy was found to be the most common neurological disorder in our study and was similar to Hongkong study. The incidence of epilepsy is lower than that in Hongkong study ${ }^{2}$ and higher than that in Delhi study ${ }^{4}$. This disparity the trimesters and the postpartum period $^{4}$. In our study majority of cases [48.1\%] were seen in the third trimester. Primarily GTCS constituted the commonest type, constituting $59.25 \%$, consistent with the incidence of previous study $59.38 \%{ }^{9}$. There is a variation in the reports of incidence of Status epilepticus during pregnancy and puerperium $-0.8 \%$ 9and $31.8 \%{ }^{4}$ and 4 [14.81\%] in our study. This can be explained by lack of awareness in the public, inadequate medical resources, inability to purchase drugs and poor compliance.

Regarding drug therapy, monotherapy with the appropriate drug and least effective dose to the epilepsy syndrome is recommended during pregnancy ${ }^{8}$. Polytherapy increases the incidence of major and minor fetal malformations-around 3\% for one drug, $5 \%$ for two, $10 \%$ for three and greater than $20 \%$ in women taking more than three antiepileptic drugs ${ }^{10}$.

In our study, $51.85 \%$ of the woman with pregnancy and epilepsy were not receiving any treatment at the time of presentation and $37.03 \%$ were on monotherapy compared to $28.1 \%$ and $59.38 \%$ in other study ${ }^{9}$ which is higher and lower respectively. $11.1 \%$ were on polytherapy similar to $12.5 \%$ of other study ${ }^{9}$. Most of our patients receiving monotherapy were on phenytoin as it is dispensed in Government hospital.

Eclampsia: The occurrence of eclampsia is higher [63.6\%] than that in Hongkong study [44-48\%] ${ }^{11}$. Of the two cases that had focal neurological deficits, one had ischemic stroke and the other hemorrhagic stroke. Pre eclampsia (PE)/Eclampsia (E) were found to be an etiological factor for stroke in previous studies ${ }^{12}$, and are the major leading cause of stroke in the peripartum maternal mortality and morbidity ${ }^{13}$. Eclampsia was found to be associated with ischemic stroke in $24-47 \%$ of cases and cerebral hemorrhage in $14-44 \%^{11}$. Association between history of PE and ischemic stroke remote from pregnancy necessitates close monitoring of women beyond postpartum period ${ }^{14}$. Cerebral hemorrhage is reported to be the most common cause of death in patients with eclampsia ${ }^{12}$. These observations indicate careful 
evaluation of PE/E cases to detect additional cerebral infarction or hemorrhage. Maternal outcome was good in rest of the cases with adverse fetal outcome in six cases.

Cerebrovascular Disorders: Reported incidence of stroke during pregnancy and the puerperium ranges from 5-67 per 100,000 pregnancies ${ }^{15}$, contributing to more than $12 \%$ of all maternal deaths ${ }^{12}$. Fetal and maternal outcome may be adversely affected with premature delivery, fetal mortality, and residual neurological deficits $^{15}$. $89 \%$ of pregnancy related strokes occur at the time of delivery or postpartum ${ }^{12}$. Out of two cases with past $\mathrm{h}$ /o hypertension, one had stroke in the third trimester and the other two weeks postpartum. All cases of cerebral venous thrombosis were seen postpartum.

Takayasu' arteritis is a rare vasculitis, in which both ischemic and hemorrhagic strokes are reported ${ }^{16}$. Our patient presented in first trimester and had good outcome. Course of the disease appears to be unaffected by pregnancy ${ }^{17}$. Treatment with steroids with and without cytotoxic agents is recommended ${ }^{16}$. Cesarean section should be reserved for obstetric indication.

Neuropathies: Guillain-Barre syndrome affects 6-24/100,000 of population during pregnancy ${ }^{19}$. Incidence in pregnancy is not greater than expected in nonpregnant woman of child bearing age $^{20}$. GB syndrome is known to worsen during the postpartum period due to increase in the delayed hypersensitivity ${ }^{21}$. Relapses during subsequent pregnancies can occur. Pregnancy, labour and delivery proceed normally for most woman $^{20}$. Both plasmpheresis ${ }^{21}$ and immunoglobulins ${ }^{22}$ were used with good maternal and fetal outcome. New born children of mothers with GBS may also be effected rarely ${ }^{23}$.

Carpal tunnel syndrome is one of the commonest peripheral neuropathies of pregnancy ${ }^{20}$. The incidence increases during pregnancy ${ }^{24}$ with prevalence around $2 \%{ }^{25}$. Symptoms usually start in the latter half of pregnancy and improve in the postpartum period.
Recurrence can occur in subsequent pregnancies. Most improve within a few weeks postpartum ${ }^{20}$. In our subject, associated diabetes and hypothyroidism might have contributed to the occurrence of symptoms in the first trimester. She improved with conservative management.

Facial Palsy: An increase in the incidence of idiopathic facial palsy during pregnancy and postpartum period was found in previous studies $^{2,26}$, and in third trimester and immediate postpartum in recent study ${ }^{27,28}$. Prognosis is excellent and similar to that observed in nonpregnant patients ${ }^{20}$. Favourable results with oral prednisolone were reported ${ }^{2}$ but opinions against steroid therapy also exist ${ }^{29}$. The association of idiopathic facial palsy and gestational hypertension was noted previously $^{30}$. Our patient presented in the third trimester and labour was induced in view of severe gestational hypertension.

Chorea Gravidarum (CG): Chorea gravidarum is a generic term for chorea of any cause starting during pregnancy. CG begins after the first trimester in half of patients, spontaneouslyabatesinapproximately one third before delivery and resolves as the pregnancy progresses and may recur in 1 in 5 women in subsequent preganancies $^{31}$. Maternal and fetal risks are not elevated. Elective termination is not indicated ${ }^{32}$. In our study both cases had good outcome.

Tubercualr Meningitis (TBM): TBM in pregnant woman is associated with increased maternal and perinatal mortality. Favourable outcomes reported with early diagnosis and treatment ${ }^{4}$. Our patient presented relatively late with mild hydrocephalus but improved with medical management. She delivered a premature baby, and had residual right sided seventh cranial nerve palsy.

Hypokalemic Periodic Paralysis (HKPP): Pregnancy and delivery have been reported to exacerbate $\mathrm{HKPP}^{34}$ and firm data on management is lacking ${ }^{35}$.
Myotonia Congenita: A case of myotonia congenita complicated by still birth was reported ${ }^{36}$. Our patient had normal delivery without any maternal and fetal adverse effects.

As the referred patients from various departments were also evaluated referral bias cannot be avoided. Many of previous studies included PE/E related strokes under CVD. We have included them under PE/E as it is a well-established clinical entity in the resources for work up and follow up in the general hospital setting. The number of cases in the study is small and a longer duration of study will reveal more neurological disorders. In view of the broad range of the neurological disorders occurring during pregnancy, a single study is unlikely to show all the entities. As such each study contributes its own component to the spectrum of neurological diseases in this context.

\section{REFERENCES}

1. Page B.Pennel.Neurology illness and pregnancy. ed Page. B. Pennel. Neurology clinics vol 22(4) New Delhi Elsevier $2004 \mathrm{ix}-\mathrm{x}$.

2. To W K, Cheung RT.Neurological disorders in pregnancy. Hongkong Med.J 1997; vol 3(4):400-408.

3. BfocF. Neurologic disease and pregnancy. Nervenarzt.1997;70(12):1062-71

4. Gupta S, Rohatgi A, Sharma SK, Gurtoo A. A Study of neurological disorders during pregnancy and puerperium Annals of Indian Academy of neurology 2006;9:152-157.

5. S. Srinivasan K, Ramamurthy B. Neurological disorders during pregnancy and puerperium $\mathrm{J}$ Assoc Phys India 1971;19:705-13.

6. Janaki.S,Thomas L.Neurological implications in pregnancy and puerperium J Assoc Phys India 1963;11:128-37.

7. Agarwal K. Neurological disorders in pregnancy and puerperium $\mathrm{J}$ Assoc Phys India 1971;19:705-13.

8. Sanjeev V Thomas" Epilepsy and pregnancy current series. Mar2002. vol182

9. Thomas SV, Indrani L, Devi GC, Jacob 
S, Beegum J,Jacob P, Kesavadas K, Radhakrisnan K, Sarma P S. Pregnancy in women with epilepsy: Preliminary results. Kerala Registry Epilepsy and Pregnancy .Neurology India.2001:49(1).

10. Linda J. Stephen, Marti J. Brodie. Selection Of antiepileptic drugs in adults. ed Steven C.Schachter.Neurologic clinics. 27(4) New Delhi.Elsevier 2009 967-992.

11. Peter W.Kaplan.Neurologic aspects of eclampsia .ed Page B Pennel.Neurologic clinics.(22) New Delhi Elsevier 2004:84161.

12. S D Treadwell, V Thanvi, TG Robinson. Stroke in pregnancy and the puerperium. Postgrad Med J 2008;84:238-245.

13. Vilela $P$, Duarte J, Goulao A.Cerebrovascular disease in pregnancy and puerperium. Acta Med Port.2001 Jan-Feb;14(1):49-54.

14. Brown DW et al. Preeclampsia and the risk of ischemic stroke among young women: results from The stroke prevention in young women study.Stroke.2006 April;37 (4):1055-9.

15. Tanya N. Turan,Barne Jy. Stern Stroke in pregnancy Ed Page B Pennel. Neurologic clinics (22) New Delhi Elsevier2004;821-840.

16. James Donaldson, Nora S Lee, Areterial and venous stroke associated with pregnancy. Ed Lesley KramerDay. Neurologic clinics Philadelphia,vol 12, No3 Philadelphia, W,B Saunders company 1994 583-599.

17. Bassa A,Desai DK, Moodley J.Takayasu's disease and pregnancy. Three case studies and review of the literature. S Afr
Med J. 1995 Feb;85(2):107-12.

18. Hauth JC, Cunningham FG, Young BK.T akayasu's syndrome in pregnancy. Obstet Gynecol 1997 Sept ;50(3):373-5

19. Bahdur A, Nupur Guptha, Deka D, Mittal S, Successful maternal and fetal outcome of Gullain-Barre syndrome complicating pregnancy.Indian Jn Med Sci 2009;63:517-18.

20. Goyal V, Misra BK, Singh S, Prasad $\mathrm{K}$, Behari $\mathrm{M}$, Acute inflammatory demyelinating polyneuropathy in patients with pregnancy. Neurol India 2004;52:283-4.

21. Richard B Rosenbaum, James O Donaldson. Peripheral nerve and neuromuscular disorders.(ed) Lesley Kramer Day. Neurologic clinics vol 12(3) Philadelphia, Saunders WB.1994 p46177.

22. Yamada Ha, Noro N, Cato EH, Evin $\mathrm{Y}$, Cho K.Fujimoto SI Massive intravenous immunoglobulin treatment in pregnancy complicated by Gullain-Barre syndrome. Eur J Gynecol Reprod Biol.2001 Jul 1997(1):101-4.

23. Luijckx GJ, Vles J, de Bacts et al. GBS in mother and new born child Lancet 1997;349:27

24. Stahl S, Blumenfeld Z, Yarnitsky D. Carpal tunnel syndrome in pregnancy; indications for early surgery. J Neurol Sci. $1996 \mathrm{Mar} ; 136(1-2): 182-84$

25. FinsenV, ZeitlmannH. Scand J Plast Reconstr Surg Hand surg.2006;40(1):41-5

26. Hilsinger Jr REL, Adour K K, Doty HE. Idiopathic facial paralysis. Pregnancy and menstrual cycle. Ann 0 tol 1975;84:433-42
27. Vrabec Jllsaacson B, Van Hook JW. Bell's palsy and pregnancy. Otolaryngol Head Neck Surg 2007.2007 Dec;137(6);858861

28. Shapiro L, Yudin MH, Ray JG.Bell's palsy and tinnitus during pregnancy: predictors of pre-eclampsia. Act Otolaryngol (Stockh) 1999;119:647

29. ShawM, NazirF, Bonel. Bell's palsy: a study of treatment advice given by neurologists. J Neurol Neurosurg Psy 2005;76:293-294

30. D.Shmorgun,W.S Chan and J.G Ray. Association between Bell's palsy in pregnancy and pre-eclampsia. QJ Med 2002;95:359-362

31. Lawrence I. GolbeP. Pregnancy and movement disorders. Ed Lesley Kramer Day. Neurologic clinics. Vol 12(3)1994 p497-507

32. Marsha S. A. Shrith, Marian L Evatt "Movement disorders in pregnancy" Neurol clin 22 (2004). 783-798.

33. Schnarwyler B, Hammer. Chorea gravidarum F.1: Gynacol Rundch.1991;31(3):331-6

34. Parant O, Grandjean S, Castagno R, Letourneur B, Desprats $R$, Larrue V.Hypokalemic periodic paralysis and pregnancy; perinatal management. A case report. J Gynaecol Obste Biol (Paris) 2007 Oct;36(6):607-10.E Pub 2007 May 29

35. Levittio. Practical aspects in the management of hypokalemic periodic paralysis.J Trasl Med 2008 April 21;6:18

36. Schwartz IL,Dindfelder JR, O'Tuama L.Swift M. Recessive congenital mytonia and pregnancy. Int J Gynaecol Obstet. 1979 Sep-Oct; 17(2):194-6 